\section{Werner Maaßen wird 80 Jahre}

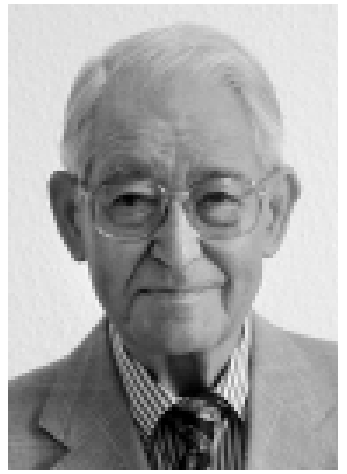

seiner Emeritierung im Jahre 1985 nicht versiegte, weist über 100 Publikationen in nationalen und internationalen Zeitschriften und Lehrbüchern auf. Mit seinen japanischen Schülern verfasste er das Standardwerk der Lungenchirurgie, den „Atlas der Thoraxchirurgie“, 1989 erschienen - in Deutsch und Japanisch.

Herr Professor Maaßen hat die Entwicklung sowohl der Thoraxchirurgie als auch der Pneumologie in Deutschland ganz wesentlich mitgestaltet. Nicht ohne Grund war er Präsident der Deutschen Gesellschaft für Thorax-, Herz- und Gefäßchirurgie, und Präsident der Deutschen Gesellschaft für Pneumologie und Tuberkulose (wie sie damals noch hieß), ein für jüngere Kollegen heute kaum noch verständliches Phänomen. Werner Maaßen war wie nur wenige in der Lage, aus eigenem praktischen Tun und aufgrund seiner breiten Ausbildung den Bogen zu spannen von der Phthisiologie zur Pneumologie und Thoraxchirurgie. Und noch heute verfolgt er die vielfältigen Bemühungen der Deutschen Gesellschaft für Thoraxchirurgie und der Deutschen Gesellschaft für Pneumologie mit wachem Interesse und Sympathie, und bringt auch gern - wenn gefragt - seinen Rat und seine Erfahrung ein.

Als Ausdruck der Wertschätzung seiner wissenschaftlichen und berufspolitischen Aktivitäten wurde er von vielen wissenschaftlichen Gesellschaften in Europa zum Ehrenmitglied und zum korrespondierenden Mitglied ernannt, eine Aufzählung würde den Rahmen sprengen, ebenso die Erwähnung aller präsidialen Ämter, die er in den nahezu 40 Jahren seines beruflichen Wirkens wahrnahm.

In dem berühmten, oben zitierten Stufengedicht von Hermann Hesse war von Durchschreiten der Räume die Rede. Es gehört zu dem erstaunlichen biologischen Phänomen „Maaßen“, dass er die Räume nicht nur durchschreitet, sondern auch durchreitet: Zwei- bis dreimal die Woche schwingt er sich noch in den Sattel und genießt das „Glück der Erde auf dem Rücken der Pferde“. Möge ihm seine körperliche Fitness, seine geistige Frische und seine heitere Altersweisheit noch lange erhalten bleiben.

Prof. Dr. N. Konietzko, Essen 